\title{
Taste avoidance and taste aversion: Evidence for two different processes
}

\author{
LINDA A. PARKER \\ Wilfrid Laurier University, Waterloo, Ontario, Canada
}

\begin{abstract}
The terms conditioned taste avoidance and conditioned taste aversion are often used interchangeably in the literature; however, considerable evidence indicates that they may represent different processes. Conditioned taste avoidance is measured by the amount that a rat consumes in a consumption test that includes both appetitive phases and consummatory phases of responding. However, conditioned taste aversion is more directly assessed with the taste reactivity test, which includes only the consummatory phase of responding. Rats display a conditioned taste aversion as conditioned rejection reactions (gapes, chin rubs, and paw treads) during an intraoral infusion of a nausea-paired flavored solution. Treatments that produce nausea are not necessary for the establishment of taste avoidance, but they are necessary for the establishment of taste aversion. Furthermore, treatments that alleviate nausea modulate neither the establishment nor the expression of taste avoidance, but they interfere with both the establishment and the expression of taste aversion. Considerable evidence exists indicating that these two measures are independent of one another. Taste avoidance may be motivated by conditioned fear rather than conditioned nausea, but taste aversion (as reflected by rejection reactions) may be motivated by conditioned nausea.
\end{abstract}

Conditioned flavor aversion learning is assumed to result from the association between a flavored solution and an illness (see, e.g., Domjan, 1998; Garcia, Hankins, \& Rusiniak, 1974). In fact, early research evaluated associations between flavors and toxic agents with known emetic properties exclusively (e.g., Garcia \& Koelling, 1966). According to Garcia (1989), the only change in physiological state that produces an aversion to the flavor of a solution is one that induces nausea-that is, one that acts on the emetic system of the midbrain and brainstem. Although rats are incapable of vomiting, they were observed to display conditioned disgust reactions (i.e., gaping, chin rubbing) when exposed to a flavor previously paired with drug-induced nausea. Conditioned disgust reactions are established by the association between the flavor and activation of the emetic system (Garcia et al., 1974).

More recently, Grill and Norgren (1978), using a more systematic test for the assessment of the palatability of fluids, showed that rats, indeed, demonstrate disgust reactions during an intraroal infusion of lithium-paired sucrose. The taste reactivity (TR) test has revealed that rats display conditioned disgust (rejection) reactions to flavored solutions that have been paired with low to high doses of lithium chloride (Berridge, Grill, \& Norgren, 1981; Grill \& Norgren, 1978; Parker, 1982), with cyclophosphamide (Limebeer \& Parker, 1999; Parker, 1998), with high doses of nicotine (Parker, 1993) and apomorphine (Parker \& Brosseau,

This research was supported by Grant OGP-92057 from the Natural Sciences and Engineering Research Council of Canada to L.A.P. Correspondence concerning this article should be addressed to L. A. Parker, Department of Psychology, Wilfrid Laurier University, Waterloo, ON, N2L 3C5 Canada (e-mail: lparker@wlu.ca).
1990), with naloxone-precipitated morphine withdrawal (McDonald, Parker, \& Siegel, 1997), and with full-body rotation (Cordick, Parker, \& Ossenkopp, 1999; Ossenkopp et al., 2003). Each of these agents produces vomiting in species that are capable of vomiting.

\section{Taste Avoidance Is Not Always Motivated by Taste Aversion in Rats}

The typical measure of flavor-illness associations is the amount of solution consumed from a bottle containing the flavored solution —conditioned taste avoidance. This measure requires the rat to approach the bottle in order to sample the flavored solution; therefore, it involves an appetitive and a consummatory phase in responding (Konorski, 1967). An alternative measure of a flavor-illness association is called the TR test (Grill \& Norgren, 1978). This test measures the orofacial and somatic reactions elicited by a flavor infused directly into a rat's mouth. The experimenter controls exposure to the conditioned stimulus (CS) flavored solution, and the rat reacts with only the consummatory phase of responding. When infused with a flavored solution previously paired with nausea, rats display conditioned disgust reactions - a direct measure of taste aversion.

Most investigators assume that the suppressed consumption of a flavor previously paired with a psychoactive drug is due to the development of an association between some aversive stimulus property of the drug and the taste of the flavored solution; therefore, the phenomenon has been called conditioned taste aversion learning. However, it has been argued that this term does not accurately define taste avoidance produced by all treatments (Grigson, 1997; Parker, 1982; Pelchat, Grill, Rozin, \& Jacobs, 1983). 
Rats not only avoid flavors paired with emetic drugs, but also learn to avoid flavors that have been paired with drugs that are not readily characterized as aversive, such as amphetamine. Rats will avoid an amphetamine-paired flavor while simultaneously demonstrating that the drug is rewarding. They prefer the amphetamine-paired place in a place preference assessment (Reicher \& Holman, 1977) and self-administer the drug (Wise, Yokel, \& DeWitt, 1976). Because Garcia et al. (1974) had developed a model to account for taste aversion produced by emetic agents, it was reasonable for early investigators to assume that the reason rewarding drugs also produce taste avoidance in rats is that they produce the side effect of nausea, which becomes selectively associated with flavors (Reicher \& Holman, 1977). Recent findings, however, suggest that this may not be the case (e.g., Parker, 1995). According to Garcia et al.'s (1974; refined in Garcia, 1989) model, feedback from nausea produces conditioned disgust; therefore, a manipulation that produces nausea should establish conditioned disgust reactions. However, taste avoidance produced by rewarding drugs is not accompanied by conditioned disgust (Parker, 1982, 1988, 1991, 1993, 1995), indicating that avoidance produced by rewarding drugs is not motivated by conditioned nausea.

Considerable evidence indicates that not all taste avoidance is accompanied by conditioned aversion to the taste when assessed with the TR test. Stimuli that produce taste avoidance in the absence of nausea do not produce an aversion to the taste. Lower intestinal discomfort (Pelchat et al., 1983), footshock (Pelchat et al., 1983), and lesions of the lateral hypothalamus (Cromwell \& Berridge, 1993), as well as reinforcing drugs (Parker, 1982; see Parker, 1995 , for review), produce taste avoidance but do not produce rejection reactions in the TR test.
Of course, one might argue that the failure to detect rejection reactions in the TR test with corresponding taste avoidance simply reflects the differential sensitivity of the measures. That is, if reinforcing drugs simply produce weaker taste-drug associations, this association may be detected in a sensitive intake test but may not be detected in a less sensitive TR test. We specifically addressed this issue in our early work. When evaluated over nine conditioning/ testing trials, rats displayed equivalent taste avoidance for lithium $(50 \mathrm{mg} / \mathrm{kg}$, i.p.) and amphetamine ( $3 \mathrm{mg} / \mathrm{kg}$, i.p.) but dramatically displayed stronger rejection of lithiumpaired taste (Parker, 1984). Furthermore, Zalaquett and Parker (1989) demonstrated that when the doses of amphetamine and lithium were adjusted to produce weaker taste avoidance with lithium $(12 \mathrm{mg} / \mathrm{kg})$ than with amphetamine $(3 \mathrm{mg} / \mathrm{kg})$, only the lithium-paired flavor elicited rejection reactions.

We, and others, have evaluated the potential for a wide range of doses of drugs that produce taste avoidance to produce place preference learning (a measure of drug reward) and conditioned rejection reactions in the TR test. Table 1 presents four quadrants depicting whether a treatment that produced taste avoidance also produced rejection reactions in the TR test or preference/avoidance in the place-conditioning test. As can be seen in the upper lefthand quadrant of the table, none of the treatments producing taste avoidance produced both conditioned rejection reactions and place preference; that is, rewarding drugs did not produce taste aversion. The lower left-hand quadrant of Table 1 presents the treatments that produced a place preference but did not produce rejection reactions, even though they produced taste avoidance. These treatments included cocaine (Mayer \& Parker, 1993; Mucha, van der Kooy, O'Shaughnessy, \& Bucenieks, 1982; Parker,

Table 1

Place Conditioning and Rejection Reactions

\begin{tabular}{|c|c|c|}
\hline Reactions & Place Preference & Place Avoidance \\
\hline Rejection and taste avoidance & none & $\begin{array}{l}\text { alcohol (novel; } 1-2 \mathrm{~g} / \mathrm{kg}, \text { i.p.) } \\
\text { amphetamine }(10 \mathrm{mg} / \mathrm{kg} \text {, i.p. })^{*} \\
\text { apomorphine }(15 \mathrm{mg} / \mathrm{kg} \text {, i.p. })^{*} \\
\text { chlordiazepoxide }(5-20 \mathrm{mg} / \mathrm{kg}, \text { i.p. }) \\
\text { cyclophosphamide }(10-40 \mathrm{mg} / \mathrm{kg}, \text { i.p. }) \\
\text { fenfluramine }(2.5-10 \mathrm{mg} / \mathrm{kg}, \text { i.p. }) \\
\text { lithium chloride }(12-127 \mathrm{mg} / \mathrm{kg}, \text { i.p. }) \\
\text { naloxone-precipitated morphine withdrawal } \\
\text { nicotine }(1.2-2 \mathrm{mg} / \mathrm{kg}, \text { s.c. })^{*} \\
\Delta \text { 9-THC }(1.5-2.5 \mathrm{mg} / \mathrm{kg}, \text { i.p. })^{*}\end{array}$ \\
\hline No rejection and taste avoidance & $\begin{array}{l}\text { alcohol (familiar; } 1-2 \mathrm{~g} / \mathrm{kg}, \text { i.p. }) \\
\text { amphetamine }(1-5 \mathrm{mg} / \mathrm{kg}, \text { i.p. })^{*} \\
\text { apomorphine }(1-7.5 \mathrm{mg} / \mathrm{kg}, \text { i.p. })^{*} \\
\text { cocaine }(5-20 \mathrm{mg} / \mathrm{kg}, \text { i.p. }) \\
\text { LSD }(0.025-0.02 \mathrm{mg} / \mathrm{kg}, \text { i.p. }) \\
\text { methylphenidate }(5-30 \mathrm{mg} / \mathrm{kg} \text {, i.p. }) \\
\text { morphine }(2-80 \mathrm{mg} / \mathrm{kg}, \text { i.p. }) \\
\text { nicotine }(0.2-0.8 \mathrm{mg} / \mathrm{kg}, 1 \mathrm{mg} / \mathrm{kg}, \text { i.p. } \\
\text { phencyclidine }(0.5 \mathrm{mg} / \mathrm{kg}, \text { i.p. })^{*} \\
\text { penobarbital }(1-20 \mathrm{mg} / \mathrm{kg}, \text { i.p. }) \dagger \\
+\Delta-9-\mathrm{THC}(0.25-1.0 \mathrm{mg} / \mathrm{kg}, \text { i.p. }) \dagger\end{array}$ & $\begin{array}{l}\text { footshock } \\
\text { naltrexone }(1-10 \mathrm{mg} / \mathrm{kg} \text {, i.p. }) \\
\text { pentobarbital }(1-20 \mathrm{mg} / \mathrm{kg} \text {, i.p. }) \dagger \\
\text { phencylidine }(2-20 \mathrm{mg} / \mathrm{kg} \text {, i.p. })^{*}\end{array}$ \\
\hline
\end{tabular}

*Biphasic drug effects across dose range. ${ }^{\prime}$ Conflicting reports. 
1993), LSD (Parker, 1996), methamphetamine (Cunningham \& Noble, 1992; Parker, 1993), methylphenidate (Martin-Iverson, Ortmann, \& Fibiger, 1985; Parker, 1991), morphine (Beach, 1957; Mucha et al., 1982; Parker, 1991), and alcohol to which the rats had been familiarized (Davies \& Parker, 1990; Reid, Hunter, Beaman, \& Hubbel, 1985). With each of these drugs, at doses that produce taste avoidance equivalent to that produced by lithium, none has been shown to produce rejection reactions in the TR test. On the other hand, as is depicted in the upper right-hand quadrant of Table 1, across a wide range of doses, a number of drugs that produced place and taste avoidance also produced rejection reactions, including novel alcohol (Cunningham, 1979; B. T. Davies \& Parker, 1990), chlordiazepoxide (Parker, Limebeer, \& Simpson, 1998), cyclophosphamide (Parker, 1998), fenfluramine (A. M. Davies \& Parker, 1993; Parker, 1988), lithium chloride (Berridge et al., 1981; Grill \& Norgren, 1978; Mucha et al., 1982; Parker, 1982, 1992; Pelchat et al., 1983), and naloxone-precipitated morphine withdrawal (McDonald et al., 1997; Parker \& Joshi, 1998). In fact, the only drugs that produced conditioned rejection reactions also produced conditioned place avoidance in rats.

Not all treatments that produce conditioned place and taste avoidance also produce conditioned rejection reactions. As can be seen in the lower quadrant of Table 1, footshock (Pelchat et al., 1983), naltrexone (Parker \& Rennie, 1992), and higher doses of phencyclidine (Barr, Paredes, \& Bridger, 1985) produced place avoidance but did not produce rejection reactions, presumably because they do not produce nausea. Furthermore, as is indicated by asterisks $(*)$ in Table 1 , some drugs produced biphasic hedonic effects; that is, at low doses, they produced a place preference, and at high doses, they produced place avoidance. Interestingly, the same doses of amphetamine (10 mg/kg, i.p.; Costello, Carlson, Glick, \& Bryda, 1989), apomorphine (15 mg/kg, i.p.; Best, Best, \& Mickley, 1973; Parker \& Brosseau, 1990; R. Smith \& Parker, 1985), nicotine $(1.2-2 \mathrm{mg} / \mathrm{kg}$, s.c.; Jorenby, Steinpreis, Sherman, \& Baker, 1990; Parker, 1991), and $\Delta-9$-THC (1.5-2.5 mg/kg, i.p.; Mallet \& Beninger, 1998; Parker \& Gillies, 1995) that produced place avoidance also produced conditioned rejection in the TR test. Finally, although the data conflict (indicated by ${ }^{+}$in Table 1) regarding the potential of pentobarbital to produce a place preference (Bossert \& Franklin, 2001) or a place avoidance (Lew \& Parker, 1998; Mucha et al., 1982), pentobarbital does not produce conditioned rejection reactions.

\section{Effects of Antiemetic Agents on the \\ Establishment and/or the Expression of Taste Avoidance and Taste Aversion}

Garcia's claim that nausea is a necessary stimulus for taste avoidance learning has been evaluated using antinausea treatments. The results have been mixed. Although Coil, Hankins, Jenden, and Garcia (1978) reported that various antinausea agents interfered with the expression of previously established taste avoidance produced by lithium chloride, others have not replicated this finding, using similar antinausea treatments (Goudie, Stolerman, Demellweek, \& D'Mello, 1982; Parker \& McLeod, 1991; Rabin \& Hunt, 1983) and different antinausea treatments (Gadusek \& Kalat, 1975; Levy, Carroll, Smith, \& Hofer, 1974; Limebeer \& Parker, 2000; Parker, Mechoulam, \& Schlievert, 2002). Furthermore, there is considerable evidence that antinausea agents also do not interfere with the establishment of conditioned taste avoidance learning (Limebeer \& Parker, 2000; Parker, Mechoulam, \& Schlievert, 2002; Rabin \& Hunt, 1983; Rudd, Ngan, \& Wai, 1998).

Serotonergic antagonists. Although conditioned taste avoidance may not be attenuated by antinausea treatments, conditioned taste aversion (as reflected by conditioned rejection of the taste) is consistently attenuated by such treatments. One of the most effective antinausea treatments used by human chemotherapy patients is the serotonin [5- $\left.\mathrm{HT}_{3}\right]$ antagonist, ondansetron, which also interferes with toxin-induced vomiting in ferrets (Higgins, Kilpatrick, Bunce, Jones, \& Tyers, 1989). Limebeer and Parker (2000) found that ondansetron interfered with the establishment of lithium-induced conditioned rejection reactions, presumably by interfering with nausea during conditioning, and with the expression of conditioned rejection reactions, presumably by interfering with conditioned nausea during testing (Limebeer \& Parker, 2000). Pretreatment with ondansetron did not modify rejection reactions elicited by unpalatable quinine solution, suggesting that it did not merely modify the palatability of the CS solution. Furthermore, the suppression of conditioned rejection reactions by pretreatment with ondansetron was not merely a state-dependent effect, because even when rats were administered ondansetron prior to conditioning and prior to testing, suppression of rejection reactions occurred (Limebeer \& Parker, 2000).

Although ondansetron interfered with the aversive affective reactions of gaping and chin rubbing in rats, Limebeer and Parker (2000) reported that it did not interfere with either the establishment or the expression of conditioned taste avoidance, when assessed with either a onebottle or a two-bottle test. In fact, ondansetron suppressed rejection reactions among rats during a consumption test, but it did not modify the amount consumed. Therefore, the dissociation between the antinausea effects on taste avoidance and taste aversion cannot be attributed to differences in the delivery of the taste CS; conditioned rejection reactions were suppressed by the antinausea treatment whether the taste was presented by bottle or by infusion. This is important because of recent reports (Cubero, Thiele, \& Bernstein, 1999; Schafe, Thiele, \& Bernstein, 1998) that the neural structures critical for taste avoidance learning may differ on the basis of the method of CS solution delivery (intraoral or bottle).

Ondansetron altered the affective significance of sucrose, resulting in suppressed conditioned rejection in the TR test. Using an outcome devaluation task, Balleine, Garner, and Dickinson (1995) similarly reported that ondansetron changed the affective significance of a lithium- 
paired sucrose. Thirsty rats were trained to leverpress and chain-pull for sucrose and saline solutions concurrently, before being injected with lithium chloride. They were then reexposed to both solutions in the absence of the lever and chain, one after injections of the vehicle and the other after injections of ondansetron. In a subsequent extinction choice test on the levers and chains, the rats performed more of the action whose training outcome was reexposed under ondansetron than of the other action. Ondansetron attenuated the outcome devaluation effect, presumably by modifying the conditioned affective change in the significance of the lithium-paired taste on reexposure.

Cannabinoids. The therapeutic potential of cannabinoids (CBs) in the treatment of nausea resulting from chemotherapy has been the subject of considerable interest. Anecdotal accounts and early clinical trials have indicated that marijuana reduces nausea in such treatment. In collaboration with Raphael Mechoulam of the Hebrew University of Jerusalem, we evaluated the role of CBs in the control of nausea. Marijuana contains approximately 60 cannabinoids, including the psychoactive component, $\Delta$-9-tetrahydrocannabinol(THC). A low dose $(0.5 \mathrm{mg} / \mathrm{kg})$ of THC eliminated the establishment of conditioned rejection, as well as the expression of previously established conditioned rejection elicited by a cyclophophamidepaired flavor (Limebeer \& Parker, 1999). Cyclophosphamide is an agent used in chemotherapy treatment in humans.

Another major CB found in marijuana is cannabidiol (CBD); however, unlike THC, cannabidiol does not produce psychoactive effects (Mechoulam, 1970). CBD, unlike THC, does not bind to cannabinoid receptors; it may act by blocking the reuptake of anandamide, an endogenous CB (Bisogno et al., 2001). CBD and a more potent synthetic version, cannabidiol-dimethy heptyl, interfered with both the establishment and the expression of conditioned rejection reactions, but not with taste avoidance (Parker, Mechoulam, \& Schlievert, 2002). The effective dose of CBD (5 mg/kg, i.p.) was also the most effective dose to alleviate arthritic pain in an animal model (Malfait et al., 2000). Furthermore, the potent synthetic CB agonist HU-210 interfered with conditioned rejection reactions in rats, and the $\mathrm{CB}_{1}$ receptor antagonist SR-141716A blocked this effect . Most interesting, the antagonist actually potentiated lithium-induced conditioned rejection, suggesting that the endogenous CBs may play a role in the regulation of nausea (Parker et al., 2003).

\section{Two-Process Model: Avoidance and Aversion}

Rats avoid consumption of flavors paired with most changes in physiological state, be they emetic changes or pleasurable changes (Hunt \& Amit, 1987; see Parker, 1995 , for a review). On the other hand, rats display conditioned rejection reactions only during exposure to a flavor previously paired with drugs that produce emesis in other species (Parker, 1982; Pelchat et al., 1983; see Parker, 1998 , for a review). Antiemetic agents consistently interfere with the establishment of conditioned rejection, pre- sumably by interfering with lithium-induced nausea during conditioning, and with the expression of conditioned rejection, presumably by interfering with conditioned nausea during testing (Limebeer \& Parker, 1999, 2000; Parker, Mechoulam, \& Schlievert, 2002). However, antiemetic agents modify neither the establishment nor the expression of conditioned taste avoidance (Goudie et al., 1982; Limebeer \& Parker, 2000; Parker, Mechoulam, \& Schlievert, 2002; Rabin \& Hunt, 1983; Rudd et al., 1998; however, see Coil et al., 1978). That is, drugs that should reduce lithium-induced nausea do not interfere with lithiuminduced taste avoidance.

If rats learn to avoid a flavor paired with lithium in the absence of nausea, what might be responsible for avoidance of the taste? An early theory, which attempted to explain paradoxical reports that reinforcing drugs produce taste avoidance, suggested that any novel change in state signals danger to the rat, a species that cannot vomit (e.g., Gamzu, 1977; Hunt \& Amit, 1987). A flavor paired with this change in state comes to signal danger (e.g., Pelchat et al., 1983), resulting in subsequent avoidance of that taste. Since antinausea treatments do not interfere with the establishment or the expression of conditioned taste avoidance produced by emetic drugs, it appears that such a mechanism may account not only for taste avoidance based on reinforcing drugs, but also for taste avoidance produced by emetic drugs. Nausea produces conditioned rejection of the taste, but it appears to be independent of avoidance of the taste.

Taste avoidance in rats may result from any novel change in state (be it hedonic or aversive) that follows intake of a novel taste. This suggestion is fortified by a recent finding with an animal that vomits in response to toxin exposure. Parker, Corrick, Limebeer, and Kwiatkowska (2002) reported that the Suncus murinus (house musk shrew) develops taste preference, rather than taste avoidance, when a novel saccharin flavor is paired with high doses of amphetamine or morphine, which also produce a place preference in this species. Yet the shrew avoids saccharin that is paired with lithium chloride (J. E. Smith, Friedman, \& Andrews, 2001). Since rats, unlike shrews, are incapable of vomiting, it has been suggested that they have evolved a highly sensitive first line of defense (Davis, Harding, Leslie, \& Andrews, 1986) that signals danger any time a novel food is tasted that is followed by a change in physiological state. This first line of defense results in avoidance of that novel food in the future. Davis et al. suggested that the defense against toxins is organized into a tiered system that is designed to protect the organism against increasing penetration by toxins. The first line of defense is external to the gastrointestinal tract and is mediated by smell and taste receptors that can produce the effects of nausea and avoidance of the toxin. The second level of defense is intragastric and is mediated by gastric chemoreceptors, and the third line of defense lies within the vascular system and is mediated by the chemoreceptor trigger zone within the central nervous system. The second and third lines of defense may produce the effects 
of nausea, decreased gastric motility, vomiting, and avoidance of the toxin.

Although laboratory rats do not vomit, they do avoid tastes previously paired with wide-ranging stimuli. Davis et al. (1986) proposed that the first line of defense in the rat (i.e., smell, taste) is extremely highly developed and that therefore, perhaps as a result, the second and third lines have become redundant and are now nonfunctional. In the laboratory rat, it is known that gastric afferents respond to physical and chemical (intragastric copper sulfate and cisplatin) stimulation that precedes vomiting in emetic species, such as the ferret (Blackshaw \& Grundy, 1993; Davis et al., 1986; Grundy, 1998). Furthermore, 5$\mathrm{HT}_{3}$ antagonists that block vomiting in ferrets disrupt this neural afferent reaction in both ferrets and rats. In the rat, the detection mechanism is present, but the vomiting response is absent (Davis et al., 1986). Because the primary defense mechanism is so highly tuned, the animal no longer needs to rely on the other two lines of defense downstream, so that, in this animal, the latter are no longer effective (Davis et al., 1986).

But in the laboratory, we trick our experimental subjects by injecting them with a drug that produces an effect not normally encountered during food consumption. For instance, we inject the rat with a significant dose of amphetamine after its consumption of a saccharin solution. In this animal, which has evolved a highly tuned first line of defense, it is not surprising that the rat responds to this change in physiological state by avoidance of the saccharin that preceded the insult. On the other hand, the shrew, which vomits in response to gastrointestinal and bloodborne toxins, does not avoid saccharin or sucrose solution paired with amphetamine; in fact, it develops a preference for the drug-paired taste. Taste avoidance in the rat may be the result of conditioned fear, rather than conditioned nausea, even when produced by nausea-inducing treatments.

\section{Conclusion}

Although rats do not vomit, they do display conditioned rejection reactions upon reexposure to a flavor previously paired with treatments that produce vomiting in emetic species (see Parker, 1998). Treatments that do not produce nausea do not produce these conditioned rejection reactions when paired with a flavored solution, even at doses that are titrated to produce taste avoidance equivalent to that produced by lithium chloride (Parker, 1982, 1995; Pelchat et al., 1983). Since they are exclusively elicited by emetic treatments (such as rotation; Cordick et al., 1999), we have argued that these conditioned rejection reactions reflect conditioned nausea in rats.

The strongest evidence for the hypothesis that conditioned nausea is the primary elicitor of conditioned rejection reactions is selective reduction in conditioned aversive reactions by antinausea treatments. However, these data are also compatible with the possibility that nausea might act by modulating the perception of taste palatability, making the taste itself aversive, rather than directly eliciting nausea. Indeed, it is possible that both conditioned nausea and an aversive affective change in the palatability of the taste itself are produced by treatments that produce nausea. Certainly, unconditionally aversive taste stimuli (such as bitter quinine) also elicit rejection reactions in the TR test. However, if nausea-induced conditioned rejection reactions are simply a shift in palatability, antinausea treatments should also attenuate unconditioned palatability shifts, but they do not. Unconditioned rejection of bitter quinine was not modulated by pretreatment with the antinausea treatments (Limebeer \& Parker, 2000; Parker \& McLeod, 1991).

It is interesting to note that when a flavor is paired with a chemotherapeutic drug, hedonic ratings of liking of the flavor are more predictive of nausea in human chemotherapy patients than is consumption of the flavored solution (Schwartz, Jacobsen, \& Bjovberg, 1996). Furthermore, humans who report nausea as a symptom of food allergies not only avoid the food, but also report a conditional distaste for the food (Pelchat \& Rozin, 1982). On the other hand, when the allergic symptoms are mouth sores or hives, the subjects avoid the food but do not dislike its taste. Nausea appears to be a necessary condition for the establishment of conditioned dislike for a taste.
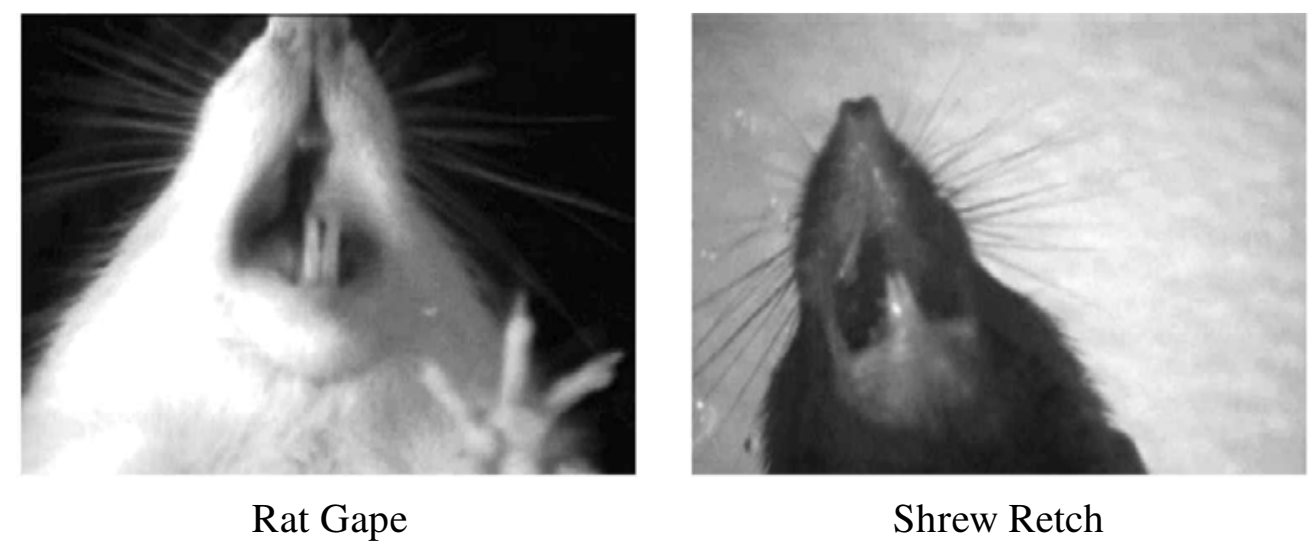

Figure 1. The orofacial characteristics of the rat gape are very similar to those of the shrew retch. Unlike the rat, the shrew vomits in response to emetic stimulation. 
According to Balleine et al. (1995), two processes may be involved in taste aversion learning. The first is a Pavlovian process in which the taste becomes a danger signal, and the second is an evaluative or incentive process in which the affective significance of the taste changes. It is likely that the signal process accounts for taste avoidance and that the change in affective significance accounts for rejection reactions. These processes are apparently independent, because avoidance can occur without conditioned rejection (Parker, 1995) and conditioned rejection can be attenuated by antiemetic treatments that do not affect conditioned avoidance (Limebeer \& Parker, 2000; Parker, Mechoulam, \& Schlievert, 2002).

The TR test measures the affective value of the drugpaired flavor independently of approach responses. It measures consummatory responding independently of preparatory responding (Konorski, 1967), incentive value independently of signal properties (Balleine et al., 1995; Garcia, 1989), and/or liking independently of wanting (Robinson \& Berridge, 1993). Nausea appears to selectively modify conditioned rejection reactions in the TR test, but not consumption in a standard taste avoidance test, because antinausea treatments attenuate the former, but not the latter. As has been suggested by many authors (e.g., Berger, 1972; Grant, 1987), nausea is neither necessary nor sufficient for the establishment of taste avoidance learning. Our results suggest that nausea may, in fact, be irrelevant to taste avoidance learning, although it is necessary for the establishment of a conditioned dislike for the taste.

Among the conditioned rejection reactions elicited by a flavor paired with an emetic treatment, gaping is the most prevalent. Indeed, the orofacial topographies of the rat gape and the shrew retch are very similar, as is depicted in Figure 1. Indeed, Travers and Norgren (1986) reported that the muscular movements involved in gaping mimic those seen in species capable of emetic reactions. It is conceivable that the gaping response in the rat represents a vestigial precursor to vomiting in this animal, which no longer displays the full vomiting response.

\section{REFERENCES}

Balleine, B. W., Garner, C., \& Dickinson, A. (1995). Instrumental outcome devaluation is attenuated by the anti-emetic ondansetron. Quarterly Journal of Experimental Psychology, 48B, 235-251.

Barr, G. A., PARedes, W., \& Bridger, W. H. (1985). Place conditioning with morphine and phencyclidine: Dose dependent effects. Life Sciences, 36, 363-368.

BEACH, H. D. (1957). Morphine addiction in rats. Canadian Journal of Psychology, 11, 105-112.

BERGER, B. D. (1972). Conditioning of food aversions by injections of psychoactive drugs. Journal of Comparative \& Physiological Psychology, 81, 21-26.

Berridge, K. C., Grill, H. J., \& Norgren, R. (1981). Relation of consummatory responses and preabsorptive insulin release to palatability and learned taste aversions. Journal of Comparative \& Physiological Psychology, 95, 363-382.

Best, M., Best, P., \& Mickley, G. (1973). Conditioned aversion to distinct environmental stimuli resulting from gastrointestinal distress. Journal of Comparative \& Physiological Psychology, 85, 250-257.
Bisogno, T., Hanus, L., De Petrocellis L, Tchilibon, S., Ponde, D. E., Brandi, I., Moriello, A. S., Davis, J. B., Mechoulam, R., \& Di Marzo, V. (2001). Molecular targets for cannabidiol and its synthetic analogues: Effect on vanilloid VR1 receptors and on the cellular uptake and enzymatic hydrolysis of anandamide. British Journal of Pharmacology, 134, 845-852.

Blackshaw, L. A., \& GRUNDY, D. (1993). Effects of 5-hydroxytryptamine on discharge of vagal mucosal afferent fibres from the upper gastrointestinal tract of the ferret. Journal of the Autonomic Nervous System, 45, 41-50.

Bossert, J. M., \& FrankLin, K. B. (2001). Pentobarbital-induced place preference in rats is blocked by GABA, dopamine and opioid antagonists. Psychopharmacology, 157, 115-122.

Coil, J. D., Hankins, W. G., Jenden, D. J., \& Garcia, J. (1978). The attenuation of a specific cue-to-consequence association by antiemetic agents. Psychopharmacology, 56, 21-25.

Cordick, N., Parker,L. A., \& Ossenkopp, K. P. (1999). Rotation-induced conditioned rejection in the taste reactivity test. NeuroReport, 10, 1157-1159.

Costello, N. L., Carlson, J. N., Glick, S. D., \& Bryda, M. (1989). Dose-dependent and baseline-dependent conditioning with $d$ amphetamine in the place conditioning paradigm. Psychopharmacology, 99, 244-247.

Cromwell, H. C., \& Berridge, K. C. (1993). Where does damage lead to enhanced food aversion: The ventral pallidum/substantia innominata or lateral hypothalamus? Brain Research, 624, 1-110.

Cubero, I., Thiele, T. E., \& Bernstein, I. L. (1999). Insular cortex lesions and taste aversion learning: Effects of conditioning method and timing of lesion. Brain Research, 839, 323-330.

Cunningham, C. L. (1979). Flavor and location aversions produced by ethanol. Behavioral \& Neural Biology, 27, 362-367.

Cunningham, C. L., \& Noble, D. (1992). Methamphetamine-induced conditioned place preference or aversion depending on dose and presence of drug. In P. B. Kalivas \& H. W. Samson (Eds.), The neurobiology of drug and alcohol addiction (Annals of the New York Academy of Sciences, Vol. 654, pp. 431-433). New York: New York Academy of Sciences.

Davies, A. M., \& Parker, L. A. (1993). Fenfluramine-induced place aversion in a three-choice apparatus. Pharmacology, Biochemistry \& Behavior, 44, 595-600.

Davies, B. T., \& Parker, L. A. (1990). Novel versus familiar ethanol: A comparison of aversive and rewarding properties. Alcohol, 7, 523-529.

Davis, C. J., Harding, R. K., Leslie, R. A., \& Andrews, P. L. R (1986). The organisation of vomiting as a protective reflex. In C. J. Davis, G. V. Lake-Bakaar, \& D. G. Grahame-Smith (Eds.), Nausea and vomiting: Mechanisms and treatment (pp. 65-75). Berlin: Springer-Verlag. DomJan, M. (1998). The principles of learning and behavior (4th ed.). Pacific Grove, CA: Brooks/Cole.

Gadusek, F. J., \& Kalat, J. W. (1975). Effects of scopolamine on retention of taste-aversion learning in rats. Physiological Psychology, 3, 130-132.

GAMZU, E. (1977). The multifaceted nature of taste aversion inducing agents: Is there a single common factor? In L. Barker, M. Domjan, \& M. Best (Eds.), Learning mechanisms offood selection (pp. 447-511). Waco, TX: Baylor University Press.

GARCIA, J. (1989). Food for Tolman: Cognition and cathexis in concert. In T. Archer \& L.-G. Nilsson (Eds.), Aversion, avoidance and anxiety (pp. 45-85). Hillsdale, NJ: Erlbaum.

Garcia, J., Hankins, W. G., \& RusiniaK, K. W. (1974). Behavioral regulation of the milieu interne in man and rat. Science, 185, 824-831.

Garcia, J., \& Koelling, R. A. (1966). Relation of cue to consequence in avoidance learning. Psychonomic Science, 4, 123-124.

Goudie, A. J., Stolerman, I. P., Demellweek, C., \& D’Mello, G. D. (1982). Does conditioned nausea mediate drug-induced conditioned taste aversion? Psychopharmacology, 78, 277-282.

Grant, V. L. (1987). Do conditioned taste aversions result from activation of emetic mechanisms? Psychopharmacology, 93, 405-415.

GRIGSON, P. S. (1997). Conditioned taste aversions and drugs of abuse: A reinterpretation. Behavioral Neuroscience, 111, 129-136.

Grill, H. C., \& Norgren, R. (1978). The taste reactivity test: I. 
Mimetic responses to gustatory stimuli in neurologically normal rats. Brain Research, 143, 263-279.

GRUNDY, D. (1998, June). Visceral afferents and their modulation in animal models of nausea and vomiting. Paper presented at the International Symposium on Nausea and Vomiting: A multidisciplinary approach. Tutzing, Germany.

Higgins, G. A., Kilpatrick, G. J., Bunce, K. T., Jones, B. J., \& Tyers, M. B. (1989). 5- $\mathrm{HT}_{3}$ receptor antagonists injected into the area postrema inhibit cisplatin-induced emesis in the ferret. British Journal of Pharmacology, 97, 247-255.

Hunt, T., \& Амiт, Z. (1987). Conditioned taste aversion induced by self-administered drugs: Paradox revisited. Neuroscience \& Biobehavioral Reviews, 11, 107-130.

Jorenby, D. E., Steinpreis, R. E., Sherman, J. E., \& Baker, T. B. (1990). Aversion instead of preference learning indicated by nicotine place conditioning in rats. Psychopharmacology, 101, 533-538.

KonORSKI, J. (1967). Integrative activity of the brain: An interdisciplinary approach. Chicago: University of Chicago Press.

Levy, C. J., Carroll, M. E., Smith, J. C., \& Hofer, K. G. (1974). Antihistamines block radiation-induced taste aversions. Science, 186, 1044-1045.

Lew, G., \& Parker, L. A. (1998). Pentobarbital-induced place aversion learning. Animal Learning \& Behavior, 26, 219-224.

Limebeer, C. L., \& Parker, L. A. (1999). Delta-9-tetrahydrocannabinol interferes with the establishment and the expression of conditioned rejection reactions produced by cyclophosphamide: A rat model of nausea. NeuroReport, 10, 3769-3772.

Limebeer, C. L., \& Parker, L. A. (2000). Ondansetron interferes with lithium-induced conditioned rejection reactions, but not lithiuminduced taste avoidance. Journal of Experimental Psychology: Animal Behavior Processes, 26, 371-384.

Malfait, A. M., Gallily, R., Sumariwalla, P. F., Malik, A. S., ANdreakos, E., Mechoulam, R., \& Feldmann, M. (2000). The nonpsychoactive cannabis constituent cannabidiol is an oral antiarthritic therapeutic in murine collagen-induced arthritis. Proceedings of the National Academy of Sciences, 97, 9561-9566.

Mallet, P. E., \& Beninger, R. J. (1998). $\Delta$-9-tetrahydrocannabinol, but not the endogenous cannabinoid receptor ligand anandamide, produces conditioned place avoidance. Life Sciences, 62, 2431-2439.

Martin-Iverson, M. T., Ortmann, R. \& Fibiger, H. C. (1985). Place preference conditioning with methylphenidate and nomifensine. Brain Research, 332, 59-67.

Mayer, L. A., \& PArker, L. A. (1993). Rewarding and aversive properties of IP versus SC cocaine: Assessment by place and taste conditioning. Psychopharmacology, 112, 189-194.

McDonald, R. V., Parker, L. A., \& Siegel, S. (1997). Conditioned sucrose aversions produced by naloxone-precipitated withdrawal from acutely administered morphine. Pharmacology, Biochemistry \& Behavior, 58, 1003-1007.

Mechoulam, R. (1970). Marihuana chemistry. Science, 168, 1159-1163.

Mucha, R. F., van der Kooy, D., O'Shaughnessy, M., \& Bucenieks, P. (1982). Drug reinforcement studied by the use of place conditioning in the rat. Brain Research, 243, 91-105.

Ossenkopp, K.-P., Parker, L. A., Limebeer, C. L., Burton, P., Fudge, M. L., \& Cross-Mellor, S. K. (2003). Vestibular lesions selectively abolish rotation-induced, but not lithium-induced, conditioned taste aversions (oral rejection responses) in rats. Behavioral Neuroscience, 117, 105-114.

PARKer, L. A. (1982). Nonconsummatory and consummatory behavioral CRs elicited by lithium- and amphetamine-paired flavors. Learning \& Motivation, 13, 281-303.

Parker, L. A. (1984). Behavioral conditioned responses across multiple conditioning/testing trials elicited by lithium- and amphetaminepaired flavors. Behavioral \& Neural Biology, 41, 190-199.

PARKER, L. A. (1988). Positively reinforcing drugs may produce a different kind of CTA than drugs which are not positively reinforcing. Learning \& Motivation, 19, 207-220.

Parker, L. A. (1991). Taste reactivity responses elicited by reinforcing drugs: A dose-response analysis. Behavioral Neuroscience, 105, 955964.
Parker, L. A. (1992). Place conditioning in a three- or four-choice apparatus: Role of stimulus novelty in drug-induced place conditioning. Behavioral Neuroscience, 106, 294-307.

PARKer, L. A. (1993). Taste reactivity responses elicited by cocaine-, phencyclidine-, and methamphetamine-paired sucrose solutions. Behavioral Neuroscience, 107, 118-129.

PARKER, L. A. (1995). Rewarding drugs produce taste avoidance, but not taste aversion. Neuroscience \& Biobehavioral Reviews, 19, 143-151.

PARKER, L. A. (1996). LSD produces a place preference and taste avoidance, but does not produce taste aversion. Behavioral Neuroscience, 109, 503-508.

PARKER, L. A. (1998). Emetic drugs produce conditioned rejection reactions in the taste reactivity test. Journal of Psychophysiology, 12, 3-13.

Parker, L. A., \& Brosseau, L. (1990). Apomorphine-induced flavordrug associations: A dose-response analysis by the taste reactivity test and the conditioned taste avoidance test. Pharmacology, Biochemistry \& Behavior, 35, 583-587.

Parker, L. A., Corrick, M. L., Limebeer, C. L., \& Kwiatkowska, M. (2002). Amphetamine and morphine produce a conditioned taste and place preference in the house musk shrew (Suncus murinus). Journal of Experimental Psychology: Animal Behavior Processes, 28, 75-82.

Parker, L. A., \& Gillies, T. (1995). THC-induced place and taste aversions in Lewis and Sprague-Dawley rats. Behavioral Neuroscience, 109, 71-78.

Parker, L. A., \& Joshi, A. (1998). Naloxone-precipitated morphine withdrawal induced place aversion: Effects of naloxone at 24 hours postmorphine. Pharmacology, Biochemistry \& Behavior, 61, 331-333.

Parker, L. A., Limebeer, C., \& Simpson, G. (1998). Chlordiazepoxideinduced conditioned place and taste aversion learning in rats. Pharmacology, Biochemistry \& Behavior, 59, 33-37.

PARKer, L. A., \& MCLeod, K. B. (1991). Chin rub CRs may reflect conditioned sickness elicited by a lithium-paired sucrose solution. Pharmacology, Biochemistry \& Behavior, 40, 983-986.

Parker, L. A., Mechoulam, R, \& Schlievert, C. (2002). Cannabidiol, a non-psychoactive component of cannabis, and its synthetic dimethylheptyl homolog suppress nausea in an experimental model with rats. NeuroReport, 13, 567-570.

Parker, L. A., Mechoulam, R., Schlievert, C., Авbott, L. A., Fudge, M. L., \& Burton, P. (2003). Cannabinoid agonists attenuate and a cannabinoid antagonist potentiates lithium-induced conditioned rejection reactions in a rat model of nausea. Psychopharmacology, 166, 156-162.

Parker, L. A., \& Rennie, M. (1992). Naltrexone-induced aversions: Assessment by the place conditioning taste reactivity and taste avoidance paradigms. Pharmacology, Biochemistry \& Behavior, 41, 559-565.

Pelchat, M. L., Grill, H. J., Rozin, P., \& Jacobs, J. (1983). Quality of acquired responses to tastes by Rattus norvegicus depends on type of associated discomfort. Journal of Comparative Psychology, 97, 140-153.

Pelchat, M. L., \& Rozin, P. (1982). The special role of nausea in the acquisition of food dislikes by humans. Appetite, 3, 341-355.

Rabin, B. M., \& Hunt, W. A. (1983). Effects of antiemetics on the acquisition and recall of radiation and lithium chloride induced conditioned taste aversions. Pharmacology, Biochemistry \& Behavior, 18, 629-636.

Reicher, M. A., \& Holman, E. W. (1977). Location preference and flavor aversion reinforced by amphetamine in rats. Animal Learning \& Behavior, 5, 343-346.

Reid, L. D., Hunter, G. A., Beaman, C. M., \& Hubbel, C. L. (1985). Toward understanding ethanol's capacity to be reinforcing: A conditioned place preference following injections of ethanol. Pharmacology, Biochemistry \& Behavior, 22, 483-487.

Robinson, T. E., \& Berridge, K. C. (1993). The neural basis of drug craving: An incentive-sensitization theory of addiction. Brain Research Reviews, 18, 247-291.

Rudd, J. A., NGAN, M. P., \& WAI, M. K. (1998). 5-HT 3 receptors are not involved in conditioned taste aversions induced by 5 -hydroxytryptamine, ipecacuanha or cisplatin. European Journal of Pharmacology, 352, 143-149.

Schafe, G. E., Thiele, T. E., \& Bernstein, I. L. (1998). Conditioning 
method dramatically alters the role of amygdala in taste aversion learning. Learning \& Memory, 5, 481-492.

Schwartz, M. D., Jacobsen, P. B., \& Bjovberg, D. H. (1996). Role of nausea in the development of aversions to a beverage paired with chemotherapy treatment in cancer patients. Physiology \& Behavior, $\mathbf{5 9}, 659-663$

Smith, J. E., Friedman, M. I., \& Andrews, P. L. R. (2001). Conditioned food aversion in Suncus murinus (house musk shrew): A new model for the study of nausea in a species with an emetic reflex. Physiology \& Behavior, 73, 593-598.

Smith, R, \& PARKer, L. A. (1985). Chin rub CRs are elicited by flavors paired with apomorphine, physostigmine, neostigmine, scopolamine and methylscopolamine. Pharmacology, Biochemistry \& Behavior, 23, 583-589.
Travers, J. B., \& Norgren, R. (1986). Electromyographic analysis of the ingestion and rejection of spid stimuli in the rat. Behavioral Neuroscience, 100, 544-555.

Wise, R., Yokel, P., \& DeWitT, H. (1976). Both positive reinforcement and conditioned aversion from amphetamine and from apomorphine in rats. Science, 191, 1273-1274.

Zalaquett, C., \& Parker, L. A. (1989). Further evidence that CTAs produced lithium and amphetamine are qualitatively different. Learning \& Motivation, 20, 413-427.

(Manuscript received July 3, 2002;

revision accepted for publication September 27, 2002.) 